\title{
DYNAMICS OF COLLECTIVE EXPLORATION IN THE ANT PHEIDOLE PALLIDULA*
}

\author{
By C. Detrain, J. L. Deneubourg, S. Goss, Y. Quinet \\ Unit of Behavioural Ecology, CP 231 \\ Université Libre de Bruxelles, 1050 Bruxelles, Belgium
}

\section{INTRODUCTION}

Foragers of large ant societies tend to be integrated into a web of chemical communication, and, we conjecture, to show extensive trail laying behaviour outside food recruitment. This factor, combined with their large number, leads to the development of a network of marks and trails in the foraging area which serve to organise their foraging activity. The foragers orient themselves principally with reference to these chemical signals, exploration being a collective rather than an individual process. This is well documented for Iridomyrmex humilis (Deneubourg et al 1990; Aron et al, in press) and the army ants (Rettenmeyer 1963; Schneirla 1971; Topoff et al 1980; Franks and Fletcher 1983; Deneubourg et al 1989). Other species may be reasonably thought to follow the same logic (Pheidologeton diversus: Moffett 1984, 1988; Solenopsis sp.: Tschinkel 1987, Wilson and Hölldobler pers. comm.; Iridomyrmex pruinosus: Hölldobler pers. comm.). This type of organisation is often correlated with polydomy, which requires permanent links between the different sub-nests.

The polymorphic ant Pheidole pallidula ( $\mathrm{Nyl}$.) is one of the most abundant Mediterranean species, whose opportunism is characterised by its night and day activity, the diversity of its diet and the flexibility of its foraging techniques which can include participation by the majors (Detrain, 1990). Because of its polydomous nature, its large colony size (several hundred individuals per subnest), and its strong trail recruitment to food sources, we felt that $P h$. pallidula fitted into this pattern, contributing to its ecological success, and would therefore form a collective exploratory trail even though such behaviour has not previously been reported. This

${ }^{*}$ Manuscript received by the editor October 12, 1990 
article presents the confirmation of this prediction, and a quantitative analysis of the mechanisms involved.

\section{Material AND Methods}

\section{Nest maintenance}

Ph. pallidula colonies were collected on the south slopes of the "Corbières" ridge (Aude, France). In the laboratory, several colonies were kept in plaster nests at a constant temperature of $22^{\circ} \mathrm{C} \pm 1{ }^{\circ} \mathrm{C}$ with a $12: 12$ hours dark-light regime. Two colonies were used for quantitative tests (Soc. 1: 2000 minors, 250 majors and 1 fertile queen; Soc. 2: 800 minors, 100 majors and 1 fertile queen). The ants were fed with brown sugar solution and dead cockroaches.

\section{Collective exploratory behaviour}

To elicit exploratory behaviour, a new bridge was placed between the nest container and a chemically unmarked sand-filled arena $(1 \times 2 \mathrm{~m})$. Photographs of the arena were taken every 3 minutes for 2 hours to study the time evolution of the exploration. The traffic in both directions on the bridge was quantified in 3 minute intervals to define recruitment curves. This experiment was repeated 5 times each with Societies 1 and 2. Six additional qualitative observations were made with other societies.

\section{Trail-laying behaviour}

To understand the mechanisms involved in the formation of the collective exploratory trail, we filmed the behaviour of workers walking both to and from the unmarked arena during the first 40 minutes, using a video-camera linked to a time-date generator displaying 1/100ths of a second ( 3 experiments on Soc 1 and 2 on Soc $2)$. The camera ( $30 \times$ magnification) was moved horizontally parallel to the bridge, following a randomly chosen ant over a distance of $\pm 10 \mathrm{~cm}$ from side-on, with a bright white back-screen to enhance the image contrast. Fuzzy images were avoided using a narrow bridge $(0.5 \mathrm{~cm}$ width). For each ant recorded, we carried out a frame-by-frame analysis with steps of $0.04 \mathrm{sec}$, noting whether the ant exhibited marking behaviour, our criterion being whether the gaster was in contact with the substrate (a classical technique, see e.g., Hölldobler and Wilson 1978; Aron et al 1989). 
RESULTS

\section{Collective exploratory behaviour}

Upon arriving in the unmarked arena, minors start exploring the part closest to the nest, behaving as individual explorers, dispersing and moving randomly (fig. 1a). As the number of explorers increases, their spatial distribution becomes inhomogenous, with areas of higher density (fig. 1b) in which a clearly-defined trail appears over a few minutes (fig. 1c). Initially, minors leave the nest and follow the trail in small groups. As the recruitment proceeds the flow of ants leaving the nest becomes more continuous. The trail is clearly visible from the column of ants connecting the nest to the edge of the explored area where the ants disperse (fig. 1d), and generally remains the only trail present during the two hours observation (in one of the 5 experiments several weak and ephemeral trails supplanted the initial one).

The existence of an exploratory recruitment is confirmed by the logistical growth of ants on the arena (fig. 2a, Soc 1). During the first part of the growth phase, the trail with groups of minors starts to appear. As the plateau is reached, the trail has become continuous. These two stages are reached, for example, after around 40 and 70 minutes on the solid curve in fig. 2a, corresponding to figs. $1 \mathrm{c}$ and $\mathrm{d}$. The maximum number of explorers on the arena varied from 400 to 700 individuals. In other words, $20-35 \%$ of the society were directly implied in the exploration of new territories. It is worth noting that at most $5 \%$ of the explorers were majors, while majors composed about $10 \%$ of the total population of workers.

For the smaller society (Soc 2), the collective exploration appears to occur differently than for the larger one. During the first minutes of each experiment, no collective pattern of exploration was observed. The weakness or even lack of recruitment is shown by the slow growth of the population on the arena (fig. $2 b$ ), and a cohesive structure did not always appear (e.g., in the experiment where the recruited population was the lowest). When the recruitment is sufficient, a first cohesive collective structure appears after roughly 2 hours (see e.g., fig. $2 b$, solid curve), compared with 40-70 minutes for the large society. This corresponds in both societies to the moment at which approximately 200 explorers are present on the arena. This exploratory trail is less frequented than with the large society, being used sporadically by small groups of 

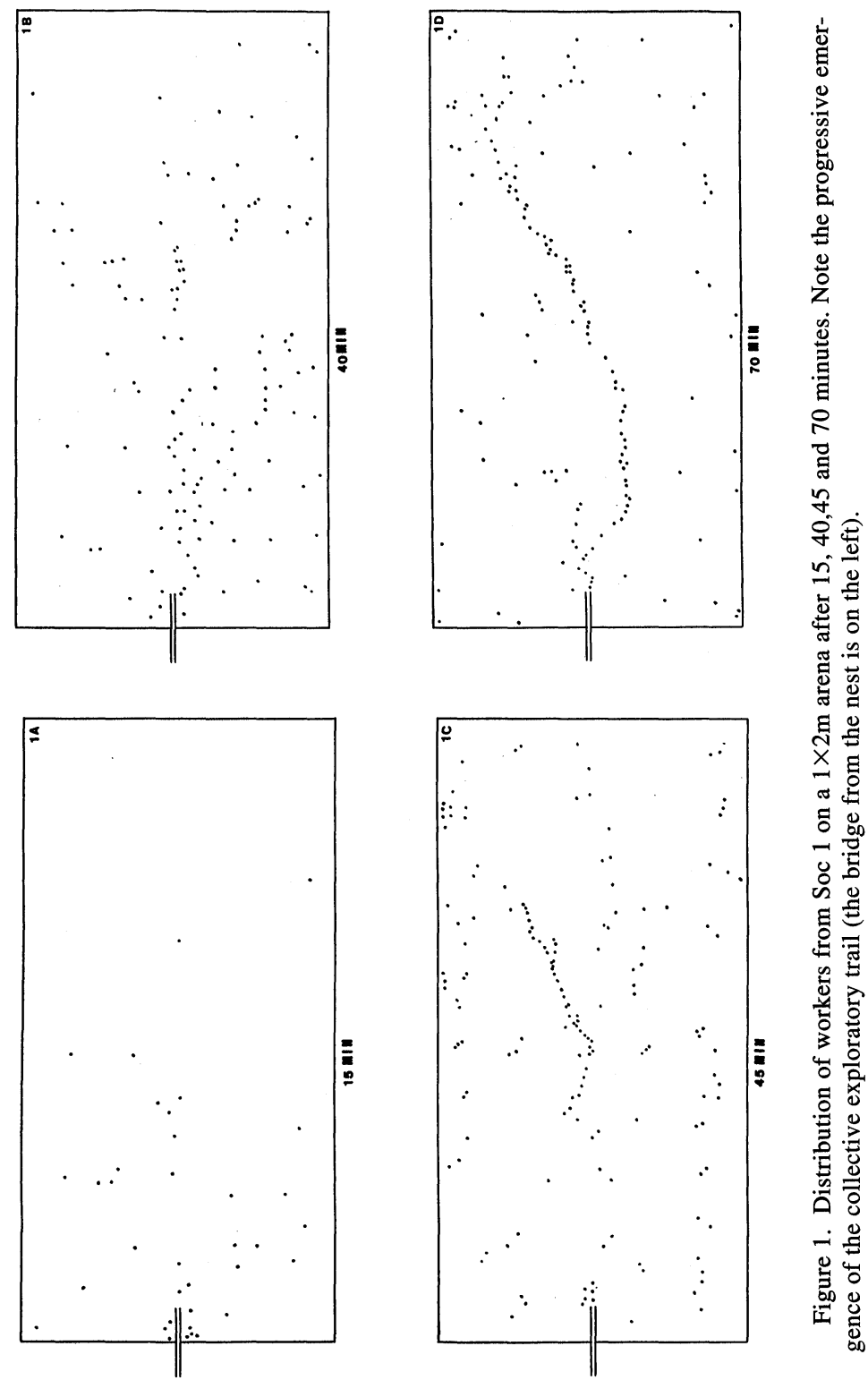

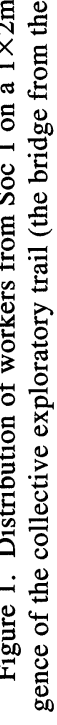



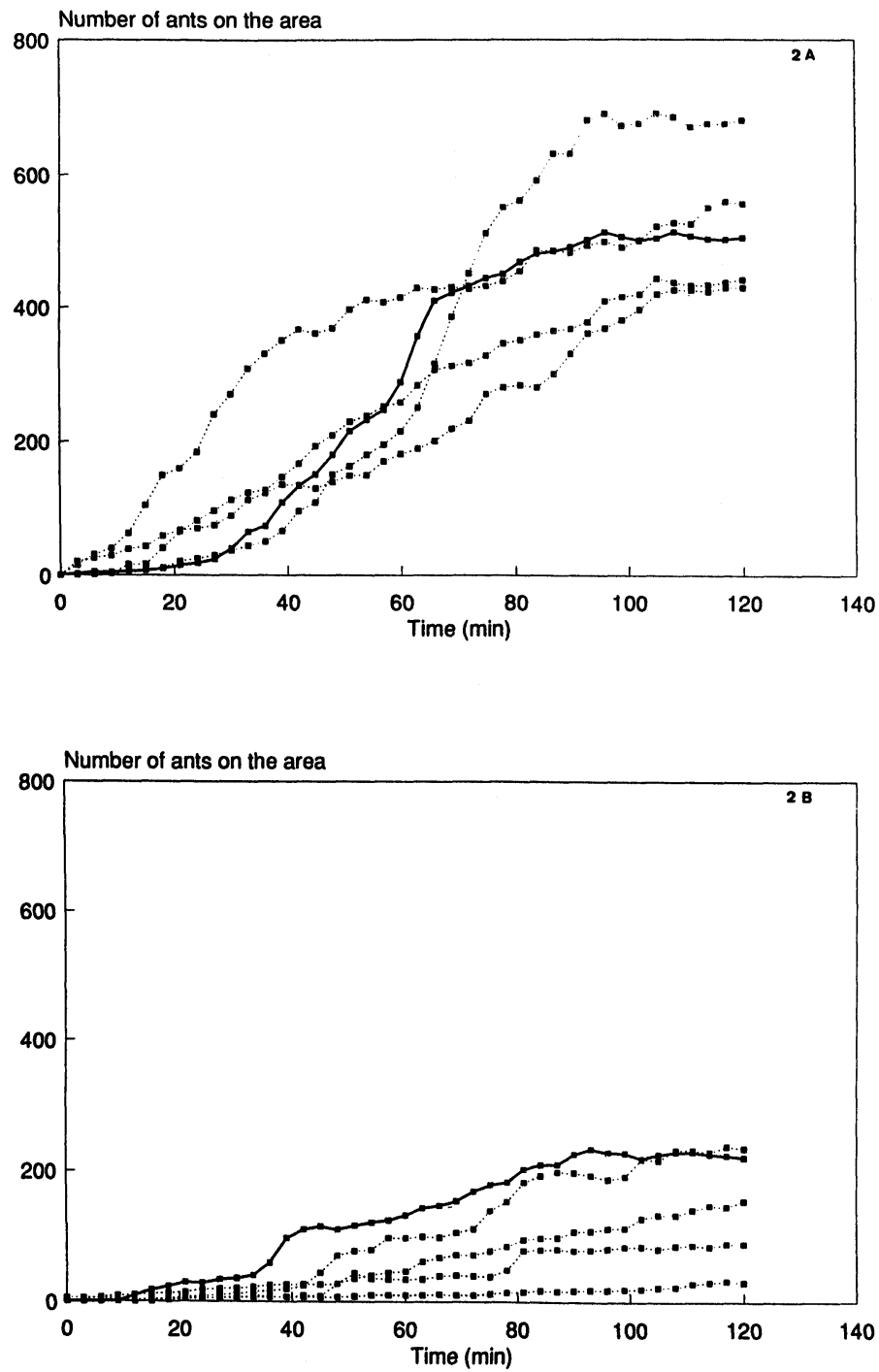

Figure 2. Time evolution of the number of workers on the arena during five experiments each on Societies 1 (fig. 2a, large colony) and 2 (fig. $2 b$, small colony). The solid curve in fig. $2 \mathrm{a}$ corresponds to the experiment in fig. 1. 
recruited ants (see step-like form of the recruitment curves in fig. $2 b)$. Finally, as in the large society, $25-45 \%$ of the nest population are present on the arena.

These results for both the small and the large societies were confirmed with other colonies. An important question that arises is whether these differences in the collective behaviour of small and large societies are due to differences in individual behaviour, or whether they are just a direct consequence of the different number of participants, the individuals having exactly the same behaviour. The following measurements were aimed at answering this question.

\section{Trail-laying behaviour}

For the large society, during the period that leads up to the emergence of the exploratory pattern, the vast majority of ants both leaving and returning to the nest exhibit marking behaviour in more than $80 \%$ of the video-frames analysed (fig. 3a). The marking towards the nest is slightly more intense. The small society gives highly similar results (fig. $3 b$ ).

\section{DisCUSSION}

Exploratory recruitment to unknown areas, as now shown for $P h$. pallidula, has been reported for different ant species, such as Leptothorax unifasciatus (Lane 1977), using tandem running, Oecophylla longinoda (Hölldobler and Wilson 1978) and Iridomyrmex humilis (Deneubourg et al 1990), using mass recruitment.

Strong interspecific differences can be found in the resulting exploratory patterns, two extreme cases being individual exploration with a more or less random distribution of explorers, e.g., Leptothorax sp. (Aron 1990), and an exploratory trail leading to a diffuse exploratory front, e.g., Iridomyrmex sp. (Deneubourg et al 1990, Aron et al, 1990), Solenopsis sp and I. pruinosus (Hölldobler and Wilson pers. comm.).

The large society of $P h$. pallidula studied above fits into this latter schematic. The smaller society, however, was seen to be less able to nucleate this pattern, this being seen to be a direct consequence of the smaller number of participants and not the result of any qualitative difference in their individual exploratory 


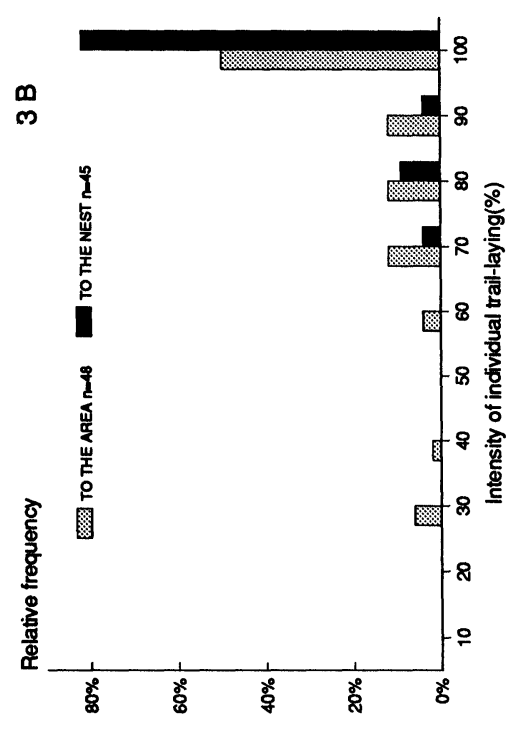

롷

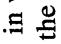

\&。

츨

ठิ

券

岁芯

递

훙

สิ

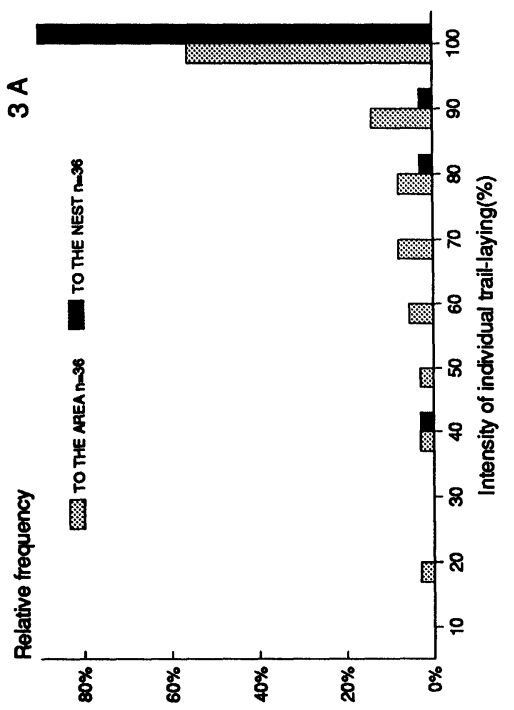

它品

근

送

.

원

范

击

过

吾

要

㞗

D.

S.

业

点

ले :

品品

点

现 
behaviour. With only a few trail-layers, the quantity of trailpheromone laid is insufficient to compensate for the loss by evaporation, adsorption, etc., and the appearance of a collective trail is inhibited. We consider that this effect is strong enough to account for the differences between the small and large societies.

On this basis, one might suppose that many species that appear to explore individually are in fact marking just as much per individual, and in a similar manner, as those species that explore collectively, but have a smaller colony size and for this reason alone are unable to generate a collective pattern. Not enough is known about exploration in different species to support or contradict this hypothesis, but indirect confirmation comes from the fact that those species that forage collectively have a large colony size (Beckers et al 1990). In fact the collective patterns of both exploration and group raiding can be understood using the same model (Deneubourg et al 1989).

We have no field data on collective exploration and its adaptive value. Collective exploration is in many ways more efficient than individual exploration, especially in a large society, and indeed we have seen it needs a large number of workers to be possible. The exploratory trail leads recruits straight to the edge of the unexplored zone and thus avoids re-exploring a zone already swept. As each explorer stays within the network of pheromone marks, they can easily find their way back to the nest and do not need a strong capacity for individual orientation.

After a winter period, or nest flooding by autumnal rainfalls, this collective exploration could allow a fast and efficient recuperation and/or expansion of the colony's territory. The exploratory behaviour also seems to be a food searching strategy. At any moment, explorers can be considered as a pool of potentially recruitable workers, closer to where the food discovery occurs than those in the nest. Furthermore, the exploratory trail helps returning workers reach the nest directly where they can recruit nestmates to new food sources. A large food item (a mealworm) was once seen in the laboratory as a starting point for an exploratory raid after an intense build-up of Ph. pallidula workers at the food item. In Pheidologeton diversus, such raiding patterns can also advance from food items or highly frequented trails without any apparent provocation (Moffett, 1988). 
The genesis of exploratory trails in the vicinity of food sources can lead in the field to the discovery of additional prey, and could explain the origin of the dense network of $P h$. pallidula trails observed (Detrain, in press). Ph. pallidula trunk-trails extend the trophophoric area and give easy access to distant regions rich in food patches. These trunk-trails could originate when exploratory trails become food recruitment trails, and are used daily as a base from which individual exploration and/or exploratory trails may extend.

Finally this collective exploration further illustrates the link between intense bi-directional trail-laying and the genesis of flexible and efficient collective patterns, and the importance of the number of participants in this process.

\section{ACKNOWLEDGEMENTS}

This work is supported in part by the Belgian National Fund for Scientific Research, the Venture Research Unit of British Petroleum, the Ernst and Victor Hasselblad Foundation, and the Belgian Program for Inter-University Attraction Poles. We would like to thank D. Vanhauwermeiren for her extensive help in the video analysis, and Professors J. M. Pasteels and G. Nicolis for their moral support.

\section{SUMMARY}

Experimental evidence is presented for the existence of collective exploration in the ant Pheidole pallidula. In large colonies, after a period of diffuse exploration, an exploratory trail linking the nest to the edge of the explored region rapidly appears and extends in stretches as the exploration advances. In a small colony, the trail is usually absent, and if it does appear it takes longer to do so and is less clearly defined. However, the individual trail-laying behaviour, as examined by video analysis, is identical in both cases, with the vast majority of explorers laying trail pheromone more or less continuously both when leaving and returning to the nest. The differences between the exploration by small and large societies of Ph. pallidula can therefore be attributed to the presence of a smaller or greater number of participants. This effect could also account for the lack of collective exploration in other species. 


\section{REFERENCES}

Aron, S.

1990. Contribution individuelle et collective dans l'exploitation du territoire chez Leptothorax unifasciatus et Iridomyrmex humilis (Hymenoptera: Formicidae). Thèse de Doctorat, Université Libre de Bruxelles. $141 \mathrm{pp}$.

Aron, S., J. M. Pasteels, and J. L. Deneubourg

1989. Trail laying behaviour during exploratory recruitment in the Argentine ant, Iridomyrmex humilis (Mayr). Biology of Behaviour, 14: 207-217.

Aron, S., J. M. Pasteels, S. Goss, and J. L. Deneubourg

1990. Self-organizing spatial patterns in the Argentine ant Iridomyrmex humilis (Mayr). In: Applied myrmecology: a world perspective. (Vandermeer R.K., Jaffe K. and Cedena A., Eds), p. 438-451, Westview Press, Boulder, Colorado.

Beckers, R., S. Goss, J. L. Deneubourg, and J. M. Pasteels

1989. Colony size, communication and ant foraging strategy. Psyche, 96: 239-256.

Deneubourg, J.L., S. Goss, N. Franks, and J. M. Pasteels

1989. The blind leading the blind: modelling chemically mediated army ant raid patterns. J. Ins. Behav., 2: 719-725.

Deneubourg, J. L., S. Aron, S. Goss, and J. M. Pasteels

1990. The self-organizing exploratory pattern of the Argentine ant. J. Ins. Behav., 3: 159-168.

Detrain, C.

1990. Field study on foraging by the polymorphic ant species $P h$. pallidula. Ins. Soc., 37: 315-332.

FRANKS, N. AND C. R. FletChER

1983. Spatial patterns in army ant foraging and migration: Eciton burchelli on Barro Colorado Island, Panama. Behav. Ecol. Sociobiol., 12: 261-270.

HÖLLDOBLER, B. AND E. O. WILSON

1978. The multiple recruitment systems of the African weaver ant, Oecophylla longinoda (Latreille) (Hymenoptera:Formicidae). Behav. Ecol. Sociobiol., 3: 19-60.

LANE, A.

1977. Recrutement et orientation chez la fourmi Leptothorax unifasciatus (Latr.): Rôle de la piste et des tandems. Thèse de 3e cycle, Dijon, 124 pp.

MOFFETT, M. W.

1984. Swarm raiding in a myrmicine ant. Naturwissenschaften, 71: 588-590.

1988. Foraging dynamics in the group-hunting myrmicine ant, Pheidologeton diversus. J. Ins. Behav., 1: 309-331.

RETTENMEYER, C. W.

1963. Behavioral studies of army ants. Kansas Univ. Sc. Bull., 44 (9): 281-465.

SCHNeIRla, T. C.

1971. Army ants: a study in social organization. (Topoff, H. R., Ed), Freeman, San Francisco.

TOPOFF, H. R., R. MIRENDA, R. DROUAL, AND S. HERRICK

1980. Behavioral ecology of mass recruitment in the army ant Neivamyrmex nigrescens. Anim. Behav., 28: 779-789. 
TSCHINKEL, W. R.

1987. The fire ant, Solenopsis invicta, as a successful "weed". In: Chemistry and Biology of Social Insects. (Eder, J. and H. Rembold, Eds), 585-588, Verlag J. Peperny, Munchen. 

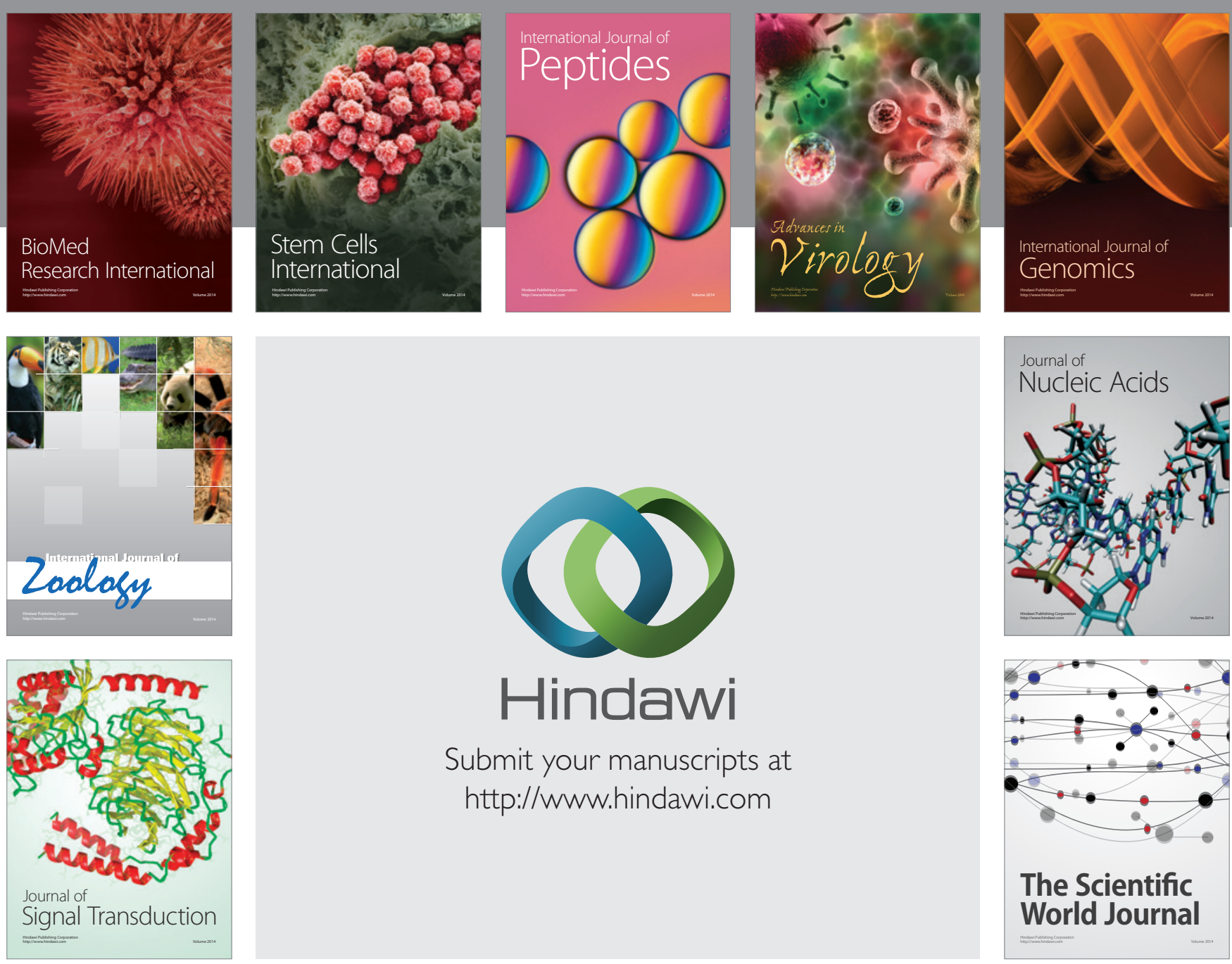

Submit your manuscripts at

http://www.hindawi.com
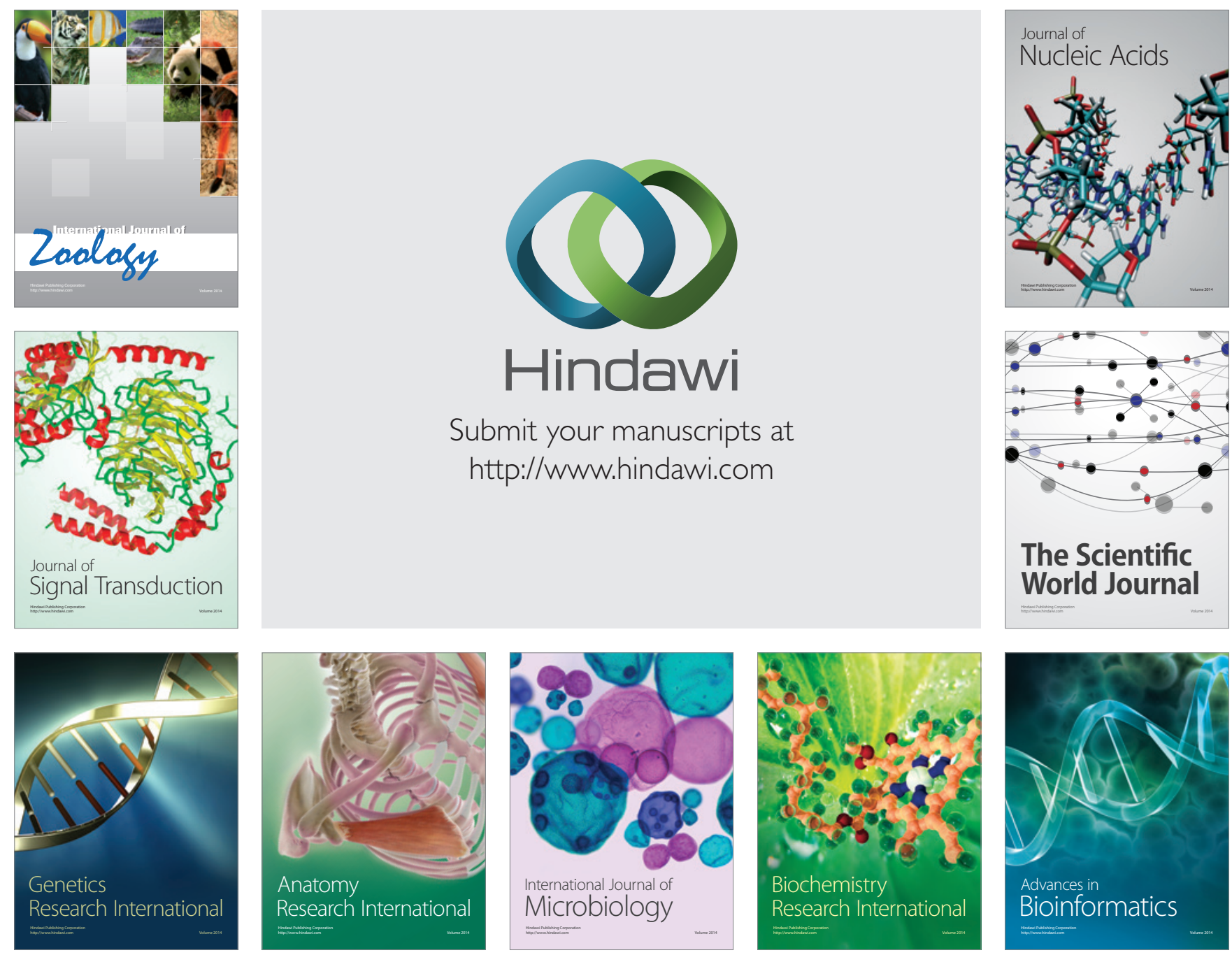

The Scientific World Journal
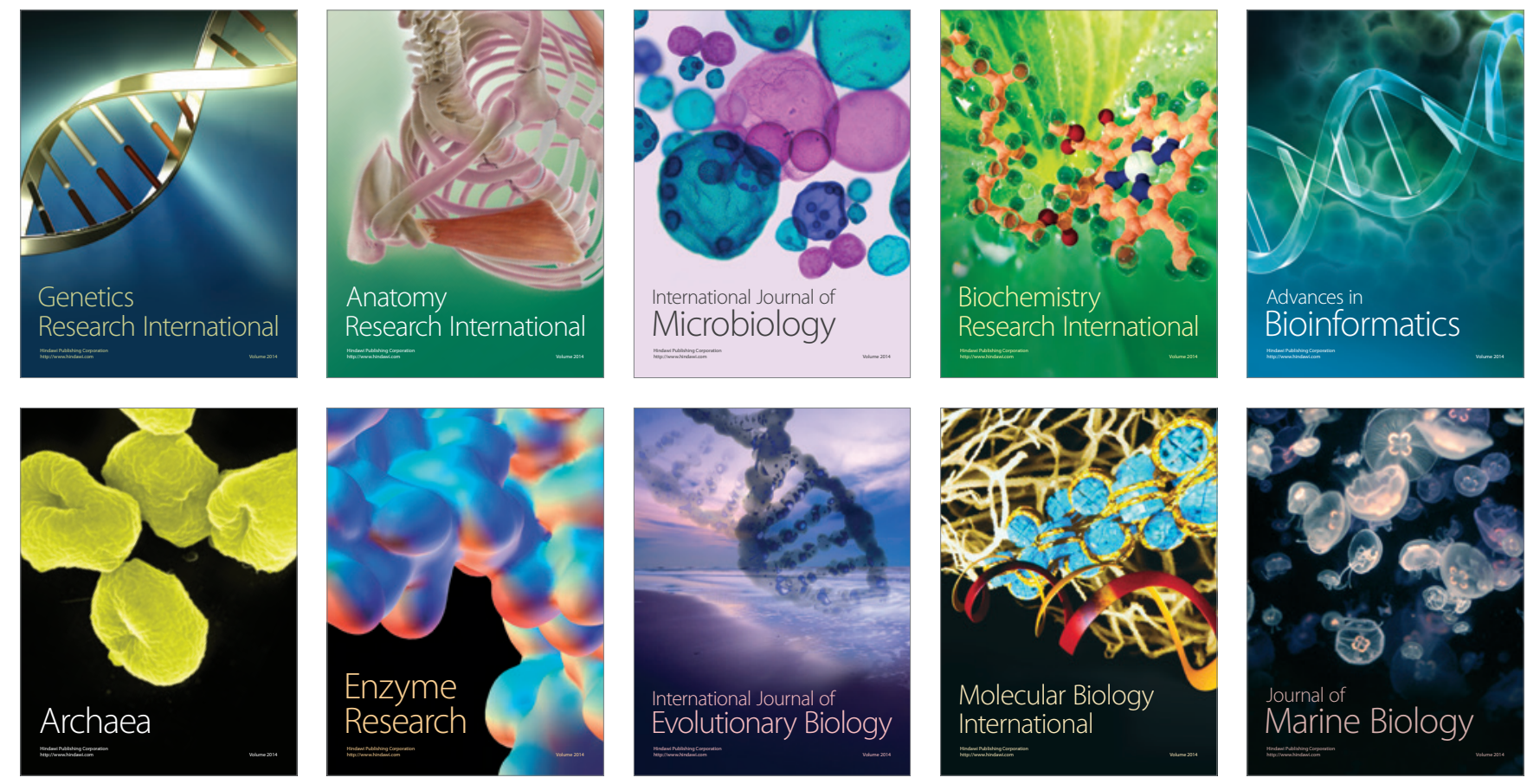